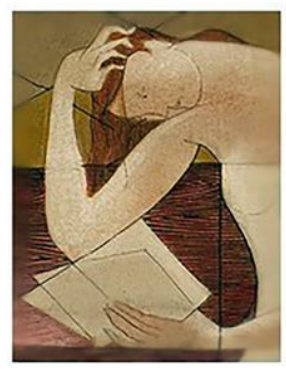

Nau Literária

crítica e teoria da literatura em língua portuguesa PPG-LET UFRGS

ISSN 1981-4526

https://seer.ufrgs.br/NauLiteraria

Vol.16, n. 2 -2020

Dossiê Literatura e Gênero

FRIEDLEIN, Roger; NUNES, Marcos Machado; ZILBERMAN, Regina (orgs.). A epopeia em questão: debates sobre a poesia épica no séc. XIX. Rio de Janeiro: Edições Makunaima, 2019. $316 \mathrm{p}$.

\title{
No ocaso das formas poéticas: a epopeia em questão
}

Rafael Brunhara ${ }^{1}$

A Epopeia em Questão, recente publicação da editora Makunaima, que cumpre a louvável tarefa de disponibilizar em seu sítio ${ }^{2}$ edições em acesso livre visando o compartilhamento e difusão de pesquisas realizadas em universidades públicas no país e no mundo, é um trabalho que reúne pesquisas de estudiosos da Alemanha, Brasil, França e Portugal, apresentadas no XII Congresso Alemão de Lusitanistas, em Mainz, em setembro de 2017. Organizado pelos professores Roger Friedlein (Ruhr-Universität Bochum), Marcos Machado Nunes (Ruhr-Universität Bochum) e Regina Zilberman (UFRGS), este é o primeiro resultado dos esforços coordenados pelo grupo de pesquisa "Discursos da épica nas culturas lusófonas do século XIX”, conduzido pelas universidades brasileira e alemã.

Os artigos que compõem esta coletânea questionam duas visões estabelecidas nos estudos literários, apresentando novas e arejadas perspectivas acerca delas: a abolição dos gêneros literários como categoria funcional para a compreensão da literatura e o entendimento de que o romance é um desenvolvimento da epopeia. No primeiro caso, observamos que a noção de gênero, embora desconsiderada pelos estudos literários contemporâneos ${ }^{3}$, foi vital até o fim do século XVIII. O sucesso ou insucesso de uma obra literária dependia de sua adequação ao gênero, isto é, do quanto ela era capaz de fazer o que outras obras do mesmo tipo faziam. Não é engano afirmar que tais concepções começam a ser desafiadas no século XIX. Este livro, ao abordar o período, oferece ao leitor a possibilidade de analisar o princípio dos questionamentos sobre as noções de gênero, a partir de um período no qual estéticas conflitantes se chocam num embate para definir o lugar que a epopeia deverá assumir nos

\footnotetext{
${ }^{1}$ Professor de língua e literatura gregas na UFRGS.

${ }^{2}$ http://www.edicoesmakunaima.com.br/.

3 Ver, por exemplo, Jameson (1981, p. 105), que afirma que tal crítica tem sido "totalmente desacreditada pela teoria e prática literárias modernas".
} 


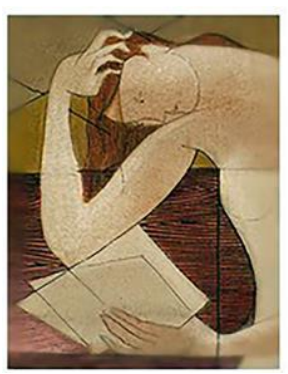

Nau Literária

crítica e teoria da literatura em língua portuguesa

PPG-LET UFRGS

ISSN 1981-4526

https://seer.ufrgs.br/NauLiteraria

Vol.16, n. 2 -2020

Dossiê Literatura e Gênero

novos tempos. Pois, segundo Nunes, em artigo deste livro, "apesar das teses sobre o seu fim, o poema épico seguirá como gênero praticado no século XIX lusófono, embora transformado sob a pressão das mudanças de paradigma estético e literário que marcam o Romantismo" (NUNES, 2019, p. 248). Assim, o estudo de um gênero literário, aqui a epopeia, pode se revelar como um instrumental teórico adequado para os estudos literários, pois nele confluem história da literatura e a recepção desta literatura $\mathrm{mesma}^{4}$, na medida em que os gêneros constituem, historicamente, "'horizontes de espera' para os leitores e 'modelo de escritura'

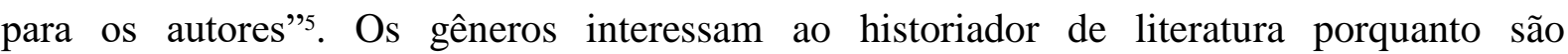
codificações destes horizontes e destes modelos, que não são uniformes, mas se redefinem a cada época. Na mesma linha, José Luís Jobim (UFF) afirma, em capítulo deste livro:

Como em nosso momento atual estamos reféns de um certo "presentecentrismo", que desvaloriza a perspectiva histórica, com frequência pensamos apenas a partir dos dois grandes sistemas classificatórios ainda vigentes na atualidade: prosa e poesia; e lírico, épico e dramático. No entanto, Hans Robert Jauss chamou a atenção sobre o quanto as teorias sobre gêneros literários têm dependido dos objetos que classificam ou de critérios canonizados seguidos no passado. (JOBIM, 2019, p. 201).

A partir desta perspectiva sobre os gêneros literários é que A Epopeia em questão, em consonância com estudos contemporâneos sobre o épico ${ }^{6}$, mostra em seus capítulos a invalidez da visão tradicional de caducidade da epopeia, apontando sua permanência no século XIX, momento em que se busca a sua reformulação, diálogo e rompimento com a tradição. Dessa maneira, o gênero nunca será confundido, assimilado ou substituído pelo romance, a forma literária privilegiada que se consagrará no período.

Tendo em vista como estas questões se desdobram em Brasil e Portugal, os trabalhos mostram um pano de fundo coeso para o lugar da epopeia no período. O volume se organiza em três eixos principais: "Moldando Camões para o século XIX”, "Desenhando uma épica para o Brasil" e "Caminhos para além do nacional".

Em Portugal, observamos a revitalização de Camões. Embora seja fato que o seu trono como grande auctoritas da epopeia nunca de fato fora ameaçado - apesar de tentativas, como

\footnotetext{
${ }^{4}$ Conforme formulação de Todorov (2018, p. 71): "Gênero é o lugar de encontro da poética geral e da história literária factual. A esse título, ele é um objeto privilegiado, o que bem poderia lhe valer a honra de se tornar a personagem principal dos estudos literários".

5 Todorov, 2018, p. 71.

${ }^{6}$ Ramalho \& Silva (2007), Neiva (2008, 2014).
} 


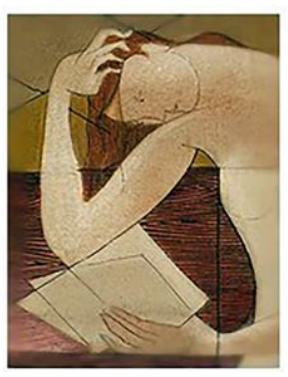

Nau Literária

crítica e teoria da literatura em língua portuguesa

PPG-LET UFRGS

ISSN 1981-4526

https://seer.ufrgs.br/NauLiteraria

Vol.16, n. 2 -2020

Dossiê Literatura e Gênero

a do controverso padre José Agostinho de Macedo com seus malfadados libelos à qualidade dos Lusíadas e com o Oriente (1814), epopeia de sua própria lavra, como nos mostra o alentado estudo de José Cândido Oliveira Martins (Universidade Católica Portuguesa), "Intensa polêmica oitocentista sobre a epopeia de Luís de Camões" - o que assistimos no século XIX é uma revalorização da epopeia camoniana, que se dá não tanto mais pelos preceitos genéricos que a enquadram como uma epopeia modelar, mas sobretudo pela atenção dada à vida do próprio Camões, em consonância com um período no qual a noção do gênio começa a suplantar as convenções poéticas herdadas do passado, como nos mostra Zilberman (UFRGS) em seu artigo "Epopeias nacionais ou heróis nacionais - eis a questão”. A vida do poeta, excepcional nos infortúnios, emerge como singular e propícia ao projeto romântico, como mostram o Camões, de Almeida Garrett, e a ficção biográfica Camões e José Índio de Ferdinand Denis, analisados pela estudiosa. Rafael de Souza Barbosa (École des Hautes Études en Sciences Sociales) chega a conclusões similares ao também abordar a figura de Denis e fazer um valioso registro da recepção e transmissão de Camões na França do século XIX, que se dá a partir da biografia Camões e José Índio, de traduções e da obra Résumé de l'Histoire Littéraire du Portugal, todas empreendidas por Denis - mostrando uma recepção da obra camoniana que se dá em estrita relação com a própria vida, então mitificada, do poeta português.

O texto de José Ricardo Vanzelli (USP) mostra-nos que essa apreciação de Camões a partir de relatos romanceados de sua vida não era unívoca no século XIX, ao abordar em seu capítulo "Camões, os Lusíadas e Camilo Castelo Branco" o prólogo ao Camões de Garrett escrito por Castelo Branco na ocasião do tricentenário do poeta dos Lusíadas, que busca revisar a biografia delineada pelos românticos. Nele, Camilo denuncia um poeta que renasce não "porque escrevera os Lusíadas, mas porque padecera d'uns amores funestíssimos" (2019, p. 123). Desmitifica, então, o poeta quinhentista, não mais o herói romântico e melancólico criado pelo século XIX, mas um português mediano vivendo na Ásia colonizada - em um movimento que desconstrói também a imagem de um passado português glorioso nas Índias.

A segunda parte da obra trata da epopeia no Brasil. O contexto que os três capítulos desta seção nos apresentam é que, diferentemente de Portugal, o espaço da epopeia no Brasil é um campo de disputas, que vincula a noção de herói coletivo da epopeia aos ideais de nação 


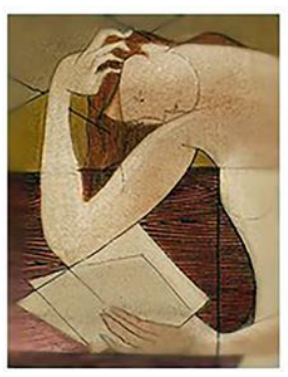

Nau Literária

crítica e teoria da literatura em língua portuguesa

PPG-LET UFRGS

ISSN 1981-4526

https://seer.ufrgs.br/NauLiteraria

Vol.16, n. 2 -2020

Dossiê Literatura e Gênero

caros ao Romantismo. O trono da epopeia estava vago e seria disputado extemporaneamente no Brasil, na aurora do Romantismo. O primeiro trabalho, de Maria Aparecida Ribeiro (Universidade de Coimbra/CLP), mostra esta disputa na polêmica entre Gonçalves de Magalhães e José de Alencar, advogando pela tese de que os romances $O$ Guarani e Iracema são "formas renovadas de epopeia" (2019, p. 168) que deixam entrever uma poética que remeterá a ela, mas a suplantará em nossa sensibilidade literária. Os romances são a resposta definitiva para as experimentações brasileiras de produzir uma épica, como comprovariam as experiências malogradas nesse sentido: uma do próprio Alencar, o projeto inacabado $O s$ Filhos de Tupã, mas sobretudo a obra de Magalhães, A Confederação dos Tamoios, cuja má qualidade se deve, segundo a autora, "seja pela falta de talento de seu autor, seja porque ninguém mais lê poemas épicos" (2019, p. 168).

Mas podemos ver que a epopeia era um gênero que operava com suas próprias regras e caminhava paralelamente ao romance por meio da sobrevivência dos regulamentos sobre o gênero em antigos manuais do século XIX, como nos diz o texto de José Luís Jobim (UFF), "O Indianismo e o épico no Brasil". O autor atesta a continuidade, no período, do discurso teórico sobre os gêneros literários, e como eles ainda são propícios para se pensar a literatura no século XIX. No contexto dos manuais de retórica brasileiros, Jobim traz exemplos que retratam a preocupação dos autores com o Indianismo, presente no horizonte de elaboração de uma epopeia nacional, mas visto nesses manuais como um elemento insuficiente para a composição do gênero. Assim, a epopeia brasileira e o romance, entendido como derivado ou substituto desta, relacionam-se, vistos pela chave do Indianismo, como "modelos negativos" de gênero (2019, p. 209). Ulisses Infante (UNESP) também cuidará de apresentar em seu capítulo a vitalidade dos discursos sobre a epopeia, centrando-se na figura de Joaquim Norberto e três de suas épicas românticas fragmentárias: Os Palmares, O Brasil e Cantos Épicos. Estas obras manifestam sua concepção do gênero a partir de modelos diversos: na primeira, Gonçalves Dias e Basílio da Gama; na segunda, a recuperação da dicção camoniana (e também do processo de mitificação do autor de Lusíadas, que ocorria concomitantemente em Portugal). A terceira obra, Cantos Épicos, possui estatuto incerto. Apesar do título, sua adequação ao gênero épico era, já em seu tempo, discutível. Entretanto, enseja um prólogo, de autoria de Fernandes Pinheiro, que, ao traçar uma genealogia para a epopeia, define a sua 


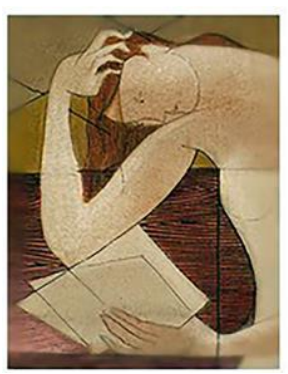

Nau Literária

crítica e teoria da literatura em língua portuguesa

PPG-LET UFRGS

ISSN 1981-4526

https://seer.ufrgs.br/NauLiteraria

Vol.16, n. 2 -2020

Dossiê Literatura e Gênero

qualidade principal como a síntese entre o lírico e narrativo. O mesmo autor, posteriormente, na obra Curso elementar de literatura nacional, exaltaria procedimentos de Gonçalves de Magalhães e Basílio de Gama. O artigo torna patente o eixo norteador desta seção do livro: a multiplicidade dos discursos e definições sobre a épica no Brasil, em função da ausência de um modelo canônico e da necessidade de repensar o gênero ao gosto da estética romântica.

Chegamos, assim, à terceira seção do livro, “Caminhos para além do nacional”, com três capítulos que, embora partam de Brasil e Portugal, investigam a abrangência universal dos temas suscitados pelo épico. É o caso do estudo de Roger Friedlein (Ruhr-Universität Bochum) que trata da questão da autorreflexividade em Dona Branca, de Almeida Garrett, obra que deixa ver em diversas instâncias - no prefácio atribuído a Filinto Elísio, em notas de fim, no seu proêmio e em expedientes intradiegéticos que projetam um leitor implícito - uma poética que preza por certo "autoctonismo saudosista" (2019, p.232) e que, se assume Ariosto como referência, ao mesmo tempo defende "uma poética do impulso e da inconstância" (2019, p. 245), inserindo-se na contramão da emulação dos modelos e de uma teorização sistemática do gênero. Percurso similar é traçado no capítulo de Marcos Machado Nunes (Ruhr-Universität Bochum), que nota que a epopeia segue como um gênero ambicionado pelo Romantismo por causa dos valores que exalta - coletividade, heroicidade, transcendência - e acomodá-la à nova estética romântica é um processo que pode ser visualizado em paratextos como prefácios, posfácios e notas que acompanhavam as obras do período. Nunes analisa duas obras, o ciclo de poemas de Teófilo Braga que se inicia com Visão dos Tempos e a Delfina do Mal de Tomás Ribeiro, para averiguar como se dá esta construção. O capítulo apresenta como esses dois autores levantam a ideia de "epopeia da humanidade" enquanto um desenvolvimento possível para o gênero durante o Romantismo, ao apresentar ideais caros a ele: o pendor universalista, a humanidade no centro, a aspiração à totalidade e à transcendência. Por fim, Luiza Lobo, em "A presença de Platão e da épica clássica em $O$ Guesa, de Joaquim de Sousândrade" também se deterá nos paratextos deste poema épico para deslindar sua poética implícita: a figura de Platão, como ideal político a ser emulado, tal como Homero é um ideal de heroísmo, e como ela se articula no contexto de uma epopeia híbrida como a de Sousândrade. 


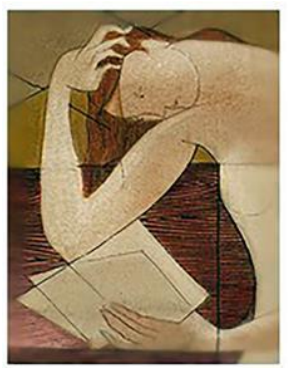

Nau Literária

crítica e teoria da literatura em língua portuguesa

PPG-LET UFRGS

ISSN 1981-4526

https://seer.ufrgs.br/NauLiteraria

Vol.16, n. 2 -2020

Dossiê Literatura e Gênero

Ao fim, os capítulos de Epopeia em Questão lançam luz a um momento essencial e decisivo das literaturas lusófonas. Podemos falar que é neste momento que concepções importantes de literatura, como os gêneros literários, começam a ser questionadas em prol de uma estética que transformaria para sempre a apreensão da literatura. No ocaso do regime dos antigos gêneros literários germina uma discussão que ocupará boa parte do século XIX e repensará o lugar da epopeia. Oferecendo análises minuciosas deste debate, A Epopeia em Questão possibilita não só revisar posicionamentos críticos acerca do gênero épico, mas também entender padrões estéticos que até hoje moldam nossa visão de literatura.

\section{Referências}

FRIEDLEIN, Roger; NUNES, Marcos Machado, ZILBERMAN, Regina (orgs.) A epopeia em questão: debates sobre a poesia épica no séc. XIX. Rio de Janeiro: Edições Makunaima, 2019.

JAMESON, Fredric. The political unconscious: narrative as a socially symbolic act. London: Methuen, 1981.

JOBIM, José Luís. "O Indianismo e o épico no Brasil". In: FRIEDLEIN, Roger; NUNES, Marcos Machado, ZILBERMAN, Regina (orgs.) A epopeia em questão: debates sobre a poesia épica no séc. XIX. Rio de Janeiro: Edições Makunaima, 2019, p. 201-216.

NEIVA, Saulo. Déclin \& confins de l'épopée au XIXe siècle. Tübingen: Narr, 2008.

NEIVA, Saulo. Épopée et modernité: sur la caducité et la réhabilitation d'un genre. Revue de critique et de theórie littéraire, vol. 9, n.3, p. 201-223, 2014.

NUNES, M.M. "Perspectiva universalista e epopeia humanitária em paratextos do século XIX português (Tomás Ribeiro e Teófilo Braga) ". In: FRIEDLEIN, Roger; NUNES, Marcos Machado, ZILBERMAN, Regina (orgs.) A epopeia em questão: debates sobre a poesia épica no séc. XIX. Rio de Janeiro: Edições Makunaima, 2019, p. 248-284.

TODOROV, T. Os gêneros do discurso. Trad. Nícia Adan Bonatti. São Paulo: Editora da Unesp, 2018. 